\title{
We are Thriving! Undergraduate Women in Engineering Student Project Teams
}

\section{Dr. Jia G. Liang, Kansas State University}

Jia Grace Liang is a faculty in the Department of Educational Leadership at Kansas State University (USA). Her research interests focus on school leadership, professional development and learning in STEM, equity for women and racial minorities, and leadership for community engagement. She holds a PhD from the University of Georgia in Educational Administration and Policy.

\section{Dr. Rick Evans, Cornell University}

Sociolinguist and Director of the Engineering Communications Program in the College of Engineering at Cornell University

\section{Dr. Stacey E. Kulesza, Kansas State University}

Dr. Stacey Kulesza is an assistant professor in the civil engineering department at Kansas State University. Dr. Kulesza teaches undergraduate and graduate courses in geotechnical engineering and is a licensed engineer in the state of Kansas. 


\title{
We are thriving! Undergraduate women in engineering student project teams
}

\begin{abstract}
For more than two decades, female participation in undergraduate engineering programs has remained stuck at $20 \%$. The research focus has been on women who either choose not to enroll or withdraw. We propose a change in focus towards women who are currently participating and thriving. These women are female undergraduate participants in extra-curricular engineering student project teams (ESPTs). Our aim is to learn more about those positive experiences as they are identified and described by the women themselves. We propose an innovative combination of qualitative research methods. We begin with sequenced semi-structured interviews focusing first on background and then their ESPT experience. Next, we employ photovoice, encouraging students to document through photographs and videos what they consider to be positive about ESPTs. And, during a follow-up interview, we ask them to assign meaning to those photographs and videos by answering questions associated with social action, the participants and their relationships, and the discourses needed for participation as well as any other mediational means necessary for performing those actions. To conclude, we present key recurring themes evident in the early data. Agency is the originating and continuing motivation. It is realized through confronting challenging problems, participating in "hands-on" doing in response, and producing tangible outcomes. Through involvement, these women experience community and understand both failure and commitment as opportunity and necessity, respectively. Finally, they experience becoming an engineer.
\end{abstract}

\section{Introduction}

In "Women in Engineering: A Review of the 2014 Literature," Meiksins et al. [1] echo the "familiar explanations for why there are relatively few women in engineering." Those explanations fall into three categories: 1) childhood socialization, arguing that engineering is generally perceived by children as a "male field;" 2) the lack of support for female students in engineering programs, leading young women to "opt for majors other than engineering;" and 3) the recognition that often women engineers "do not always thrive or remain in the field after they enter the workplace." The authors acknowledge that these are fairly common explanations. Not one of these offers a comprehensive account for the low numbers of women in engineering. And, all are related to the "vivid and powerful pipeline metaphor," still a (perhaps the) dominant frame for policy and research [2]. However, they also ask the important, if seemingly obvious question: If we know the explanations for why women remain a minority in the profession and we are making a concerted effort to respond and realize some measurable progress, then why are more women not "voting with their feet" to join the engineering community? The answer, they suggest, is that we are focused almost exclusively on the negative - why are female children not interested in engineering, why do young women not stay in engineering majors, and why do professional women engineers not thrive? What if, in addition to focusing on the negative, certainly important, we also focused on the positive - why are female children attracted to engineering, why do young women stay in engineering, and why do professional women 
engineers thrive? The objective of this research is to address this gap in the literature and to identify why some women enter, stay, and thrive in engineering.

This focus on the negative is not only incomplete but also potentially misleading. Such a focus creates a negative discourse that leaves out information on the options that are available for women academically, professionally, and organizationally. It purports to be an accurate representation of women's ability to achieve in the engineering field when it is not, in fact. Further, the pervasiveness of this discourse may deter many women from perceiving engineering as a viable option and subsequently pursuing related majors and/or occupations because they believe that failure is the most likely outcome. The predominantly negative research language is a manifestation rooted in the ideology of deficit thinking [3] - one that is prevalent in discourse related to minorities (based on race, gender, ableism, etc.). It denies the agency of minority groups, and subsequently contributes to the process of further victimization. In ways destructive of the larger project of greater inclusion, it also steers the attention to blaming and cynicism rather than activism and optimism.

It is not our intention to dispute the utility of understanding the negative, nor to suggest that there has not been a focus on the positive. However, in this brief introduction we are proposing an approach to researching women's participation in engineering that is more focused on the positive. Indeed, we have targeted a very specific and as yet very understudied context where women are actually voting with their feet to participate in engineer praxis, are becoming members of an albeit small but very active engineering community, and are embracing an authentic engineering identity.

The participation in extra-curricular engineering student project teams (ESPTs) at Cornell University has grown steadily. Currently, students from all of Cornell's seven undergraduate colleges/schools are represented, as are all fourteen engineering majors in the college. In the academic year 2016-2017, there were 24 ESPTs totaling slightly more than one thousand students. While the aggregate student participation has been increasing, the number of women students participating has also been increasing. In the academic year 2008-2009, only $15.5 \%$ of those participating in ESPTs were women. Compare that to $42.7 \%$ in 2016-2017. In addition, the number of women in leadership positions have increased dramatically across the teams. There are generally three types of ESPTs: 1) those associated with competitions, e.g., Baja SAE, Formula SAE, Violet Satellite Project; 2) those associated with service, e.g., Engineering World Health (EWH), Engineers without Borders (EWB), Engineers for a Sustainable World (ESW), and 3) those teams who are performing for a particular "client" e.g., App Development and Data Science. These ESPTs are much more than an extracurricular diversion. For participating students, they serve many important opportunities roughly correspondent to those of professional practice that we might want to make available to all women (and men). They allow students to engage in real engineering work outside of their regular courses [4]. They provide an opportunity to break out of the boundaries of the core curriculum. Students learn how to generate a production schedule, to adhere to a budget, to raise funds, and to design-test-redesign intricate technological equipment - all relevant to developing appreciation for their authentic roles within the many different expressions of engineering [5]. And, they provide students with leadership and followership experiences on projects that matter deeply to the many communities active in the search for solutions to problems [6]. 
Investigating the positive for women in this context will not only allow us to explore the embedded ideologies and the experienced values that facilitate the positive, but also how those ideologies and values get realized through the specific practices in these particular project team settings. The literature on the negative has provided important information relating to the factors that prevent women from entering, remaining, and advancing in the field of engineering. That information has served as the foundation for efforts to ensure more welcoming entry, longer retention, and greater success for women in workplace engineering contexts. If these studies can be viewed as facilitating such insights and establishing a foundation for efforts leading to change; then the proposed research could be viewed as tracing back from positive outcomes to potentially different factors enabling those outcomes and to establishing a new or at the very least more critically nuanced foundation leading to change. As such, our research question is: What can we learn from the qualities and/or features of these women's experiences in ESPTs that might help us to better understand the positive and how might that better understanding help us to design more rewarding and enduring engineering experiences and engineering identities for women (and again men)? In the following, we first introduce the methodology used for the current study. We then present the primary findings, illustrated by using data from three participants. Next, we discuss the implications, followed by conclusions and recommendations based on these findings.

\section{Methods}

To reiterate, our intent is to better understand the positive experience of women in the as of yet understudied roles and settings associated with their participation in ESPTs. Our team includes a social scientist, an educational researcher, and an engineering faculty and our research design is innovative. In brief, we adopt a feminist, activist interpretive lens. We are interested in "a particular view that builds on and from women's experiences," giving voice to those "hidden women" and encouraging an "emancipatory praxis" [7]. Such a perspective is often referred to as "standpoint epistemology." Our methodology is a multiple case study. We are interested in learning more about a "specific, unique, bounded system" [8]. In particular, ours is a collection of case studies, one involving "a number of cases jointly in order to inquire into a phenomenon, population or general condition" [8]. We use interviews and photovoice for data collection, which encourages participants to share their experience as well as provides us, as researchers, the opportunity to share in that experience.

\section{A Feminist, Activist Interpretive Lens and Standpoint Epistemology}

According to Sprague [9], standpoint epistemology "argues that all knowledge is constructed from a particular position and that what a knower can see is shaped by the location from which that knower's inquiry begins." She offers four guidelines that we have adopted for conducting research using a feminist and activist interpretive lens and a standpoint epistemology. They are: (1) focus on "everyday life as everyday actors know it;" (2) acknowledge the "partiality" of all interpretations of experience; (3) initiate and maintain "dialogue across differences;" and (4) "making things possible" through empowerment [9].

Specifically, as these guidelines frame this study, we are interested in the positive experiences in the everyday lives of these women as those experiences are related to their participation in ESPTs. We understand that the meaning of positive is always particular and partial and that what 
is particular and partial about that meaning is solely determined by those women participants. However, we also understand that while we may expect commonalities, these positive experiences will not only differ among the participants, but that in our role as researchers we will need to account for our own standpoints and those expectations of commonalities mentioned before. We will need to build and maintain "dialogues across these differences" in order to "stay connected" and perhaps, more importantly, to acknowledge our own biases in our attempts to represent those experiences [9]. Finally, we understand that also in our role as researchers (and as activists) we should support these women naming and claiming their positive experiences. We should offer through those dialogues across differences and the reflection that results in a positive experience as well - positive in the sense that the experience of the power of naming and claiming can itself be empowering.

\section{A Multiple Case Study}

Case study methodology can be defined as in-depth research that focuses on a specific and distinct "phenomenon of scientific interest" [10]. Such a phenomenon can be "a group, an individual, an organization, a community, a relationship ... or a specific project" [11]. Our particular focus was a group of individuals, and therefore a multiple case study. Those individuals were undergraduate women in ESPTs who understood themselves to have had generally (but not exclusively) positive experiences and were willing to share descriptions of those experiences. This focus required that we select a purposeful sampling strategy. Our strategy was "critical case" sampling; in other words, we attempted to identify and then select those cases, that is, women who shared important characteristics [11] of being an undergraduate student and participating in ESPTs. These women also must understand themselves to have had positive experiences and be willing to share those experiences. Less obvious but still important characteristics were that the sample cases should include women from all three types of ESPTs: competition, service, and client teams. In addition, these women should have participated in ESPTs for at least 2-3 years. Finally, and if possible, we felt that it was important to select women who had assumed some form of leadership position as part of their participation. Given that we are most interested in women who thrive in ESPTs, it seemed reasonable to assume that women who had participated for a longer period of time and who had become leads, a common reference for those who undertake leadership positions, were thriving.

Case study methodology offers two advantages we consider significant. The first is that the knowledge typically generated by case studies is "concrete and context-dependent" [12]. Given the crucial importance of the "everyday life as everyday actors know it" in standpoint epistemology or the importance of these undergraduate women's experiences as they are participating in ESPTs; attending to what was concrete and context-dependent about them was essential. The second is that case studies are particularly useful "in the heuristic identification of new variables and hypotheses" that might help us to better understand and potentially explain the phenomenon that we are studying [10]. Given that the familiar explanations for women remaining a minority in engineering fail, on the surface at least, to account for these women's increasing participation in ESPTs; the generation of new variables and hypotheses seemed an appropriately responsive way to address our research question.

\section{Interviews and Photovoice}


To recruit participants, we sent a general email to all the women participating in ESPTs. In that email, we briefly described the study purpose and asked for volunteers. We suggested that those interested contact one of us who was located at Cornell to schedule a meeting to learn more about the study. A few meetings were set with volunteers and more details about the study were shared such as the methods and the time and activity commitment necessary to participate fully. Eventually, we settled on ten volunteers. Also, prior to contacting possible volunteers, we consulted with the Institutional Review Board (IRB) to make sure that we were adhering to all IRB protocols.

With each participant, we conducted three semi-structured interviews. The first was a "life history" interview [13]. It served as an important starting point, for it allowed us to attend to the ways these undergraduate women in engineering narrated their lives. By asking questions like "Who are you?" "What are the influences on you and what influence and impact do you have?" "How do you story your life?" and "Why do you story it in this way?" - we collected "lives interpreted and made textual" by those who have lived them [13]. In addition, since engineering is generally perceived by children as a male field, we were interested in how these women understood themselves to have selected to enroll in a college of engineering and to have decided to participate in ESPTs. The second interview was a "learning journey" interview [14]. Learning journey interviews attempt to capture "the learning process experienced during time," and as such encourage the interviewee to "reflect on events and be able to relate to learning aspects" [14]. We suggested that they begin when they first learned about and/or became interested in ESPTs. Then, we asked that they share with us descriptions of their experiences as ESPT participants. Since we are told that there is such a lack of support for women in engineering that they opt out, we were interested in why these women had in effect opted in - committed themselves to the additional hours and hours of work necessary for such committed participation. Lastly, we employed a "form of participatory action research," photovoice, which "places participants behind camera lenses," encouraging them "to document elements of their lives [in project teams] within their own terms" [15]. During our third interview, we asked participants to assign meaning to those photographs and videos by answering questions associated with nexus analysis: What is the social action? Who are the participants? What are their relationships? What are the discourses of place? What are the mediational means (sometimes discourses) for performing those actions? [16]. Our aim was to learn more about the positive experiences of these women, thereby enabling us to better integrate those experiences into more traditional undergraduate engineering education.

All the interviews were transcribed and coded [11]. We employed, variously named, open or topical or descriptive coding. We made a list of all emerging themes, then grouped the themes to eliminate redundancy, and discussed any differences or disagreements among the coders. A theme passage was used to represent our findings. For the purpose of this paper, we introduce three (out of the ten) women participants, their key life histories narrated in stories and experiences with ESPTs, to illustrate the thematic findings summarized in the passage.

\section{Results}

Out of the ten women participants, $60 \%$ were in competition project teams and $40 \%$ were in service project teams. Unfortunately, we did not receive volunteers from client-based project 
teams. The majority of the women were in their second or third year with their respective project teams. All women were serving in leadership roles such as sub-team lead or project team lead. The findings of the current study reveal the following, as summarized in this thematic passage:

Agency is the originating and continuing motivation for these young women to participate in ESPTs. They understand that agency is only realized when they are confronted with challenging problems, participate in "hands-on" doing in response, and produce "tangible" outcomes. Through ESPTs and engineering praxis, then, they discover new ways to experience, indeed, to express agency - to solve problems, do hands-on things, and produce important outcomes. Through their continuing involvement, they experience community or the shared sense of responsibility to self, others, project and team emergent from their engineering praxis. They understand both failure and commitment as opportunity and necessity, respectively, and that both are critical to realizing agency. Finally, as they engage with ESPTs and in engineering praxis, they experience a powerfully rich and authentic identity, they experience becoming an engineer.

In the following, we used three cases, that is, three women participants (Nickie, Bhee, and Annie - all pseudonyms) to illustrate the overall thematic findings noted in the passage above.

Nickie is a member of an upper middleclass family with two parents (neither of whom are engineers), one sister and two brothers. She was born in the northeastern part of the United States. She differentiated herself from the other members of her family, "I was probably the least athletic person ever, so I had to find other things..." She enjoyed reading, writing and drawing. "I became very artistic ... and "was super curious" about space, ancient Egypt. She characterized her childhood by saying, "I grew up with Barbie dolls and ballet."

For Nickie, high "school became part of [her] identity." And perhaps because she was attending an all-girl Catholic school - "very antiquated ... very traditional ... a lot of history" - where the arts, writing and philosophy were very important; she felt that she was on a "liberal arts track ... [with] every single intention of becoming an English major." Still when she took a physics course as a freshman, "it kind of blew my mind how much you could do with it." Across the major events noted by Nickie on her "timeline of life history," that is, "making a solar car" in middle school, "getting [her] marble to hit exactly the other marble" in a physics class during freshman year, or the disaster-turn-to-awesome high school debate team experience, a sense of "I can and I did it" was evident. Nickie shared, "I kind of had this idea that I wanted to do something ... really, really technically difficult. ... I feel that I'm always trying to prove myself that I can do it." While the actual "hands-on experiences" was somewhat limited for Nickie before her college years, she was clear on the essence of a career she wanted to pursue. She asked herself "What's going to have the most impact?" Her answer was STEM. She noted, "I was just so incredibly attracted to the idea of making something ... of having a final product." Her rationale was "... what is what I am doing, at the end of the day, going to give back ... otherwise what is the point of doing it?"

Bhee is in her junior year and is an international student from India. Becoming an astronaut has always been what she has wanted since a very young age. "That is always my thing. Anyone who know me, ... who is even $20 \%$ close to being my friend knows," Bhee shared. Having a 
father who is an electrical engineer, according to Bhee, has played an undeniable role in her path to engineering. He is the person who first introduced her to the idea of space exploration; he is "very into photography" and so is she; he is the only person who supported her idea of coming to the United States for higher education in engineering, despite financial concerns; and he is the one in the family who provided enough freedom for her to try different things as she wanted. As the older female sibling in the family - she has a younger brother, Bhee recognized that while the gendered expectations in the Indian culture on girls are limiting, they have de facto permitted space for her exploration as "her father was not too concerned" that she has to do certain things and pick a certain career that would be good enough to support a family - one that her father bears in mind consciously when it comes to her brother, his education and development.

Bhee recalled that growing up she enjoyed reading story books; scientific fictions were not necessarily her thing then. But, somehow these "personality development" books, inspirational stories, and presentations/lectures from those guest speakers who got invited to her schools have become a way for her to "remain on the course" to become an astronaut. "You are in charge of what happens to you," Bhee noted. "They [books, stories] tell you to start doing things that will move you toward what you want to become. I have that on the first page of my notebook." She started that notebook when she was in $5^{\text {th }}$ grade, where she kept all the newspaper pages about things related to space collected over the years. There was an article that someone wrote about how to become an astronaut; Bhee put that in the notebook and followed the "recipe" by doing things that would make her an astronaut. Looking back, Bhee said she really enjoyed her high school time; she "loved physics because it explains exactly everything that is going on around you," but she "hated chemistry because it just does not make sense to [her]." Bhee explained, "If I can't physically experience it, then I don't want to study it." It was no surprise that she specifically spoke about her light bending project when we asked her to draw a life event timeline. During high school, as she learned fiber optics she came up with an idea of using tubes to bend natural light for lightening houses. She was able to present her poster based on the project at the IEEE conference which happened to be held in India. Many companies in the industry at the conference showed great interest in her ideas and proto-model. To Bhee, learning needs to be hands-on and problem solving that leads to some real-life applications. Such a view toward learning seemed to have a direct connection to how she understands engineering. When asked how she would define engineering, Bhee answered, "It would be innovation, taking what you know and creating something new. I would also say that it's creating something that helps people."

Annie grew up in the northeastern part of the United States and initially believed she was interested in the humanities. Her father is an applied mathematician, her mother a social work professor, and her brother is now an engineer. While in high school she started in a humanities program but found herself increasingly disinterested in the program projects. Although focusing on humanities, she excelled in a required Java coding course because she is "a very logical, linear, and rational person." Though this was not her "lightbulb" engineering moment, eventually she realized that she was not interested in humanities and switched to a pre-engineering program. While applying to universities she adamantly avoided universities that "were completely engineering schools" because of a fear that "everyone would be better than [her] or it would not be at all what [she] wanted and [she] would want to leave and do something else." Avoiding being corned into a major led to her choice of environmental engineering because of the overlap 
with other non-engineering environmental programs (i.e., environmental science, environmental geology). Annie noted that she enjoys environmental engineering because it is more broad than other disciplines (environmental engineers take courses from many engineering and science departments); "I think we don't necessarily dive as deeply into a lot of the subjects, but we experience a wider breadth of them...I think it gives you more perspective."

For Annie, solving big picture, global problems that affect people, and long-term change are what interests her. She insisted:

You can go and you can design a car or a building ... but environmentalism is sort of different because you're convincing people to do something they don't necessarily have to do, rather than appeasing their needs and making things easier for them. You're sort of making things harder for them. Ultimately, it's better in the long run for them and for the environment, but it's a change that they don't want to make.

Annie's description of the service team experience is different than the project teams. Her applications to "becoming" an engineer are related to real project challenges of dealing with clients. She very recently became a graduate student, about to join the Peace Corps, which is not "distinctly an engineering position" but she is "OK with it" and believes it will ultimately help with her career. She similarly related activities within EWB and AguaClara as not being directly related to the project goals, but ultimately helpful towards learning new things and understanding working with clients as "real engineers."

For these women (and other participants), agency is part of who they are, shaped by their upbringings and prior PK-12 schooling experiences. Such agency which consists of challenge, doing, and outcomes, while has initially attracted these women to engineering as they see (to a great extent, self-define) what engineering means parallel to what they want to do, continue functioning as a motivator, sustaining the women's engagement with engineering despite of challenges, and a connector/translator, bridging one's personal identity and professional identity of being an engineering. The ESPTs become engineering praxis for such continuity and translation. Like the way Bhee exemplarily put it: "I want to make a contribution that would not have been made if I chose to, say, become an English major. It's like if I didn't do it, then probably no one would have done it." Through ESPTs, the women discover new ways to experience, indeed, to express agency - to solve problems, do hands-on things, and produce important outcomes. Nickie recalled,

I started on ... Mars Rover the second week of my freshmen year. So really my whole entire college experience had been defined by the team ... if I think back to a specific time, I think back about what was going on in the team, that defines that time period, which kind of says how much of [an] influence the team has had.

Bhee, when asked what made her so passionate about this particular type of engineering - space exploration, responded: "Because it is my idea, from the scratch, it may not work, but only I can fix it because it is my idea, no one else." She further explained the excitement associated with "real challenges" and "real applications": "Different from other project teams, we work on 
different problems each year, so we can't carry over from year to year. .... All these things are challenges that NASA hasn't figured out. What we do actually contributes to something." Likewise, Annie found her ESPT experience directly shaped "how [she] view[s] environmental engineering;" she commented, "Water problems are really not very simple and they don't often come just with one problem and solution."

Furthermore, ESPTs offered community. Nickie very much respected the other students that she worked with, "the people that I have been able to work with over the years ... just really inspiring, really incredible." She also received respect in return. As part of a routine review, she was told "You know what you are talking about. Talk about it and have some confidence in yourself." This shared respect does not mean that there weren't serious confrontations. Indeed, Nickie recalled one incident during her first year:

The way we had made our parts ... some of our holes were a little bit off on this one square bracket that was ... connecting the whole E-core to the camera mast .... [So when they went to] "put it on ... my friend and I got this text from our team lead ... I think I still have it .... Like the subtitle was "THIS IS A DISGRACE." I think that 10 or 11 that night we ran to the lab, I was in my pajamas ... Freaking out, like we need to fix it all."

Likewise, Bhee emphasized, 'If I don't get things done, then I let my team down, that's not a good feeling because they are my friends now." When asked what has kept her going, she responded, "If this is a single competition, I would not think about doing it myself. .... I could it by myself, but the excitement comes when you have a group of people who are excited about the same thing." Annie had similar comments, "I'm more concerned about how the team as a whole is feeling in terms of morale, working together, having enough work to do, moving toward getting our projects done." She elaborated more,

I think we've all stayed because we've just cared about the community and making sure that we work with them to have them get something out of it, as opposed to only focusing on the fact that, "Oh yes, those designs and the research that we did sophomore year never went anywhere."

While it is not unexpected that there was/is support in ESPTs, the more prominent recurring qualities associated with community and those relationships were demand and responsibility the expectation that participants will successfully complete their tasks and respond specifically to team needs.

There were two more qualities/features of these women's experience that recurred during the learning journey interviews: failure and commitment. In the women's descriptions of their ESPT experiences, failure was constant, but (and this is important) never final. Nickie recounted failure in practice, "our holes were a little bit off on this square bracket," an example of technical failure; "our motors weren't working," a situational and unanticipated failure; "we had this whole design ... and we ended up losing ... our funding to make these wheels," a personal failure. Finally, there was even failure at competitions, “... at competition we ended up not competing in a whole category which is a whole hundred points because we had micro-controller 
issues. Similarly, Bhee remembered the year her team went to NASA to present their prototype of a tool to carry samples collected on Mars back to the space center - a designated problem for that year. Bhee did not get to go because of her international student status. Bhee felt "really disappointed" but she remained on the teleconference with the team the whole time. When a part unexpected broke in the middle of demonstration, she was there problem-solving with her project team. They were running across different stores that night on both ends trying to find a temporary replacement for the part. "We were just so happy when we did find the thing that could work." Bhee shared, "Those things are plastic, but they worked. They bought several those plastic parts just in case. We were back in the game the next day." Bhee also noted that because she decided to pursue an engineering degree in the U.S., she was turned down by companies and agencies back in India:

I guess they question why I am not getting my degree at home. We have pretty [good] engineering education [in India.] .... I wanted to do internships during summer back home since I can't really do that with NASA - that's I have always wanted, you know, the policy, I'm being international; but they [companies and agencies] did not want me either. Yeah, awkward place to be. But I figured I will figure it out. I always do.

Annie likewise discussed failure in terms of how their clients' expectations and their expectations often did not align. This had been a repeated "failure" for Annie's service team over her four-year experience. For example, she recalled when working on a small service project for a local community.

So in April we found out that they [international community] had built this system, so then all of our plans kind of went up in smoke, and I think that was really frustrating to a lot of our members...I had my [local community] experience to know that these things didn't always work out, and I think because I was a leader at that time, it was my job to tell everybody, "It's okay," and, "It's going to work out," and in the process I had to convince myself.

For Nickie and for the other women, these ESPT experiences of failure became opportunities to respond - to get better at "doing", to find an alternative way, to realize "Wow, I do need to know the answers" or to raise their own standards. Failure was an important part of engineering praxis - it defined the challenge, directed the doing and engendered better outcomes.

The other recurring feature/quality was commitment. Over and over again, the women participating in ESPTs spoke about the hours and hours and hours that they spent involved in their ESPT. Nickie refers to the Mars Rover team as a "prevalent burden." She along with the other women "didn't have weekends because we just test all weekend long. I also didn't have that much time after school because we would just go back to the lab." The commitment involved more than just time. Before her first competition, Nickie had fallen ill, "I had a 104 fever for four straight days ... [and] had to postpone my flight ... I should have gone to the hospital." Still, "I ended up going to the competition. I still had a fever, pretty sick. But, I couldn't miss competition ... I wouldn't have missed it for anything." Commitment also involved contributing. Nickie says of her fellow team members, "many were very, very intense, 
difficult, almost impossible to please. Like you wouldn't get a compliment even if you did something really well ... [but] once you got a compliment, you were like, 'Wow. Okay I actually did something really well." ESPTs require time, dedication and contribution. Not in one moment throughout our time with Bhee has she not reiterating her passion for space exploration. Annie remains a leader on the team, now as a Masters student. When asked what keeps her committed to the team, especially now as a graduate student she noted that, "I think part of it in the more self-directed aspect is I put a lot of my time and energy into this team in order to help them be successful, and I want to continue helping them do that as much as possible." Dedicating much of her undergraduate experience reminds her now that, "I want to see that my time and efforts were not wasted on a team that's going to fall apart as soon as I leave."

For participating women students, ESPTs offer many important experiences roughly correspondent to those of professional engineering practice. Students learn how to generate a production schedule, to adhere to a budget, to raise funds, to design and test and redesign intricate technological equipment. They also provide students, specifically these women, with the experience of becoming an engineer. Nickie, like the other women, was not an engineer when she began in her ESPT. Yet, she had models, peers who she could learn from, who were "inspiring, really incredible." These models were so influential that Nickie "wanted to meet them where they were ... wanted them to accept me as someone worthy." She "wanted to be those people ... I saw what I could be." She could be someone who understood and appreciated the intricacies of the design process - identifying "variables," devising ways to "test these variables," learning how "to optimize." She could be someone who understood and appreciated the importance of "decision matrices" and "a plan." Finally, she understood and appreciated the importance of "deliverables," determining if she and her team "are going to have a good product." For Nickie, however, becoming an engineer involved more. It involved "learning how to actually confront people ... having a backbone ... being able to standby something." It involved "learning how to trust people ... [and how] trusting them gives them ownership." Similarly, Annie felt that ESPT allowed her to encounter "the same problems that professionals in [her] field face." She had become more confident in her role as a team leader, as she noted, "What was very inspiring to [her] toward becoming a leader is seeing all these other women older than [her] who were leaders." Likewise, when Bhee was asked if she currently felt like an engineer, she responded:

When I did my intern, I was a freshman, everyone babied me, praised me on how much I know because they did not want to stretch me; they made me feel that I know enough to finish the project. I felt that I was treated like a would-be engineer. [in my project team] When you do the project here, you are in control. Whatever your design is what your project team has to make it. It's all the resources, consequences, everything is yours. So, yes, I feel way more like an engineer.

The women learn how to identify different resources when encountering challenges and use these resources strategically. Bhee shared, "If I do not know something, I go google, library, friends, professors are the last. It's not that professors would not help, it's just they seem to have some many things on them." The women learned how to work across different groups, entities, and perspectives. "I learned a really important lesson on how crucial it is to have the back and forth [communications] and to have a partnership that is committed to also helping you with this 
project." Annie noted in her interview, "What we do on service teams-you do get some skills; you learn some knowledge about the technical aspects ..., but the main thing that you really get out of it is ... how to successfully have good teamwork."

\section{Conclusions}

Through our illustration of three women participants, Nickie, Bhee and Annie's, stories, revealing the results of our research through a multi-case study, we have tried to answer our research questions: To learn about the qualities/ features of these women's experiences relevant to and in ESPTs and how those positive experiences might help us to design more rewarding and enduring engineering education experiences, curricula and identities for women (and men). We believe that the answers to both questions are contained in our thematic passage. Foremost, we should foster experiences of agency that are realized through challenges, opportunities for handson doing, and actual outcomes. All elements should become progressively more demanding and require a deeper and broader understanding of engineering praxis - one that is only possible if we encourage the development of an enduring community or communities. It is through their continued participation in these communities, responding to the demands and fulfilling their responsibilities that they experience a range of models for ways to become and be engineers. We must encourage failure as opportunity, rather than as a somewhat catastrophic and/or final event. We need to require commitment - ask that they give their time and dedicate themselves to making a contribution. Finally, we need to provide occasions/opportunity/space and time for them to reflect and become aware of their own becoming. This may have been the most powerful experience that ESPTs offer to students. These data indicated that this was an important reason why these women thrived. A final note: None of these ESPT environments were free of sexist attitudes and/or behaviors. Some of the environments were less overly sexist, while others were more. However, what empowered these women in those environments are the above qualities/features of their experiences in ESPTs. In one way or another, these women were empowered to respond in a way that transformed that environment, despite the pervasiveness of sexism. Although the results herein present three stories from one university, we are expanding our study. We are currently interviewing women leaders in ESTPs from Kansas State University, a four-year land-grant institution in the Midwest. The preliminary results highlight many of the same themes in the thematic passage presented herein.

\section{References}

[1] P. Meiksins, P. Layne, K. Beddoes, B. Acton, M. Lewis, A. Masters, and M. Roediger, “A compendium of the SWE annual literature reviews on women in engineering: 16 years of analysis and insight from the SWE magazine," Magazine of the Society of Women Engineers, https://research.swe.org/wp-content/uploads/2018/03/SWE-Lit-Review-Compilation-2017.pdf

[2] G. Lichtenstein, H. Chen, K. Smith, and T. Maldonado. "Retention and persistence of women and minorities along the engineering pathway in the United States.” In A. Johri and B. Olds (Eds). Cambridge handbook of engineering education. Cambridge, UK: Cambridge University Press, 2014. 
[3] R. Valenica, The Stanford series on education and public policy. The evolution of deficit thinking: Educational thought and practice. Bristol, PA: The Falmer Press/Taylor \& Francis, 1997

[4] C. Foor, S. Walden, D. Trytten, R. Shehab, "You choose between Team A, good grades, and a girlfriend - you get to choose two! How a culture of exclusion is constructed and maintained in an engineering design competition team," in ASEE Annual Conference and Exposition, Atlanta, GA, 2013.

[5] D. Mikesell, D. Sawyers, and J. Marquart, J., "External Engineering Competitions as Undergraduate Educational Experiences," in ASEE Annual Conference and Exposition, San Antonio, TX, 2012.

[6] K. Wolfinbarger and R. Shehab, "What behaviors and characteristics do engineering student competition team members associate with leadership?," in ASEE Annual Conference and Exposition, Seattle, WA, 2015.

[7] V. Olesen, "Feminisms and models of qualitative research." In N.K. Denzin and Y.S. Lincoln (Eds). Handbook of qualitative research. Thousand Oaks, CA: Sage Publications, Inc, 1998

[8] R. Stake, "Qualitative case studies." In N.K. Denzin and Y.S. Lincoln (Eds). Strategies of qualitative inquiry. Thousand Oaks, CA: Sage Publications, Inc, 1998.

[9] J. Sprague, Feminist methodologies for critical researchers: Bridging Differences. New York, NY: Rowman \& Littlefield, 2016.

[10] A. George and A. Bennett, Case studies and theory development in the social sciences. Cambridge, MA: MIT Press, 2005

[11] J.W. Creswell, 30 essential skills for the qualitative researcher. Thousand Oaks, CA: Sage Publications, 2016.

[12] J. Case and G. Light, "Emerging methodologies in engineering education research," Journal of Engineering Education, vol 100, no 1, pp. 186-210, 2011.

[13] I. Goodson and P. Sikes, Life history research in educational settings: learning from lives. New York, NY: Open University Press, 2001.

[14] H. Adriansen, "Timeline interviews: A tool for conducting life history research," Qualitative Studies, vol 3, no. 1, pp. 40-55, 2012.

[15] A. Latz, Photovoice research in education and beyond: A practical guide from theory to exhibition. New York, NY: Routledge, 2017 
[16] C. Scollon, E. Diener, S. Oishi, and R. Biswas-Diener, "Emotions across cultures and methods," Journal of Cross-Cultural Psychology, vol 35, pp 304-326, 2004 